\title{
Injury Rates, Patterns, Mechanisms, and Risk Factors Among Competitive Youth Climbers in the United States
}

\author{
Ashley M. Barrile, MD; Sing-Yi Feng, MD; Jo-Ann Nesiama, MD; Craig Huang, MD \\ Department of Pediatrics, Division of Pediatric Emergency Medicine, UT Southwestern Medical Center, Dallas, Texas
}

\begin{abstract}
Introduction-Competitive rock climbing is a fast-growing sport. Despite comprehensive reviews on adult climbing-related injuries, few pediatric-specific reviews exist, and studies exclusively on competitive youth climbers are needed. Objectives of this study include 1) estimating the injury rate (IR); 2) describing injury patterns and mechanisms; and 3) identifying injury risk factors in competitive youth climbers.

Methods-The study design was cross-sectional. Competitive youth climbers were included. Participants completed an anonymous questionnaire to document climbing injuries over the preceding 12 mo. Demographic data and data regarding injuries were collected. The IR was calculated. Analyses were performed to assess association between injury and multiple variables. Multivariate logistic regression was completed for significant variables to control for exposure time.

Results-The IR was 2.7 injuries per 1000 climbing hours. Hand/Finger injuries were most frequent; chronic overuse was the most common etiology. Injury severity was low overall. Risk factors significantly associated with climbing injury were climbing discipline (bouldering $>$ sport/lead climbing), return to climbing while still in pain, finger taping, higher number of hours climbed per session and per year, climbing at higher bouldering difficulties, and unsupervised climbing.

Conclusions-The IR in competitive youth climbers was found to be lower than previously reported but higher than suggested by adult studies or those that exclude chronic injuries. Findings are consistent with types, severity, and mechanisms reported in other studies. Modifiable risk factors, especially return to climbing while still injured, warrant further prospective investigation.
\end{abstract}

Keywords: pediatrics, rock climbing, sports injuries, competitive rock climbing, injury risk factors

\section{Introduction}

Indoor competitive climbing is a fast-growing youth sport. As of July 2019, over 4300 youth (athletes <19 y of age) competed worldwide, ${ }^{1}$ and average athlete age is decreasing. ${ }^{1,2}$ Its inclusion in the 2020 Summer Olympics further increased its professionality and influence training regimens, injury rates, and injury profiles. ${ }^{2-5}$

Despite the high level of competition, youth climbers are more prone to making errors, underestimating objective risks, and sustaining injury owing to numerous

Corresponding author: Ashley M. Barrile, MD, University of Texas Southwestern Medical Center at Dallas, Pediatric Emergency Medicine, 2752 Barrington Circle, Las Vegas, NV 89117; e-mail: barrile.ashley@gmail.com.

Submitted for publication June 2020.

Accepted for publication September 2021. well-described factors. ${ }^{1,2,3,5}$ A study specifically examining youth climber injury showed greater than twice the risk of injury in competitive climbers vs recreational ones. ${ }^{6}$

Several comprehensive studies and reviews exist for adult climbing-related injuries, but few specifically describe patterns, rates, and risk factors of injury in youth climbers or include only climbers aged $\leq 18$ y. A 2018 meta-analysis on pediatric climbing injuries highlighted this knowledge gap in light of the need to obtain an accurate picture of injury risk and severity; the analysis called for future studies to determine injury rates relative to activity level to enact preventative safety measures for youth competitive climbers. $^{3}$

This study attempts to obtain, in a very limited way, early pediatric-specific data regarding competitive climbers by estimating rates, patterns, mechanisms, and risk factors of injury. 


\section{Methods}

This was a retrospective, cross-sectional study to estimate the current frequency and impact of injuries sustained by competitive youth climbers (age 5-18 y). The primary objectives were to 1) estimate the rate of injuries per hour climbed; 2) describe the patterns and mechanisms of injury; and 3) identify risk factors for injury among children who participate in competitive rock climbing.

The "injuries in competitive youth climbers questionnaire" obtained data and was modified from a validated, international questionnaire on climbing injuries in adolescents. ${ }^{6}$ Any added questions or segments were reviewed by a group of competitive climbers, coaches, pediatricians, a youth athletic trainer, and a physical therapist for face validity $(n=15)$. The institutional review board at UT Southwestern Medical Center approved the study. Participation in the anonymous survey was explicitly voluntary. Completion was accepted as consent to participate.

The electronic survey was sent by email to coaches of youth climbing teams across the United States for distribution to their athletes via secure link. Information about participation was also posted online in climbing forums. Because the exact number of athletes approached could not be determined owing to the use of a secure link posted in climbing forums, the response rate was calculated as the percentage of completed surveys vs unique clicks of the link.

We used a timeframe of the preceding 12 mo when describing injuries reported, based exclusively on participant/parent recollection over this time period. The survey was distributed from February through April 2020 via REDCap (an electronic survey software), and results were returned to the study investigators for analysis.

The study focus was on indoor climbing (lead and bouldering) in climbers $\leq 18$ y old. All respondents of this age who are current members of a US climbing team (or were members within the past $12 \mathrm{mo}$ ), who had competed in the past 12 mo or planned to compete in the next competitive season, and who completed the mandatory survey portions were included. There were no additional specific exclusion criteria.

Exposure was defined as competitive climbing participation. The primary outcome measure was selfreported injury sustained during climbing in the past 12 mo. Injury was defined as any pain or physical complaint and was characterized as acute ("single injury, pain, or physical complaint" that could be quantified in terms of time of onset or related to a specific event) or chronic ("ongoing pain and/or physical discomfort").
The survey collected the following information:

- Demographic information and medical history

- Participation in climbing disciplines

- Climbing time

- Injury prevention measures used

- Percentage of climbing time spent under direct adult supervision

- Types, anatomic locations, and mechanisms of injury

- Time to return to climbing, injury status at return, and athletes' reasons for returning

- Treatments required

- Difficulty of climbing being undertaken (using the Hueco/V scale for bouldering, which begins at V0 and increases to V14+, and the Yosemite decimal scale, which begins at 5.4 and increases to $5.15+$, for sport/ lead climbing)

- Level of competition

- Other sport participation and injuries sustained during those sports

A previous study evaluating general injury rates and patterns in youth climbers enrolled 50 competitive climbers. ${ }^{6}$ This was used as our minimum sample size because total population and effect size were unknown.

Descriptive data are reported as mean \pm SD for normally distributed continuous data, median (IQR) for ordinal data, or percentage, as appropriate. All data obtained were self-reported.

Potential risk factors evaluated for athlete-reported injury included demographic information, climbing exposure/hours, other sport participation, discipline, difficulty, competitive level, climbing while in pain, preventative measures undertaken, and supervision. Factors were evaluated independently against acute, chronic, and multiple injuries reported, as well as against all injuries (inclusive of acute and chronic).

Inferential statistics were determined for these potential risk factors and their relationships to reported injury. A significance level of $P<0.05$ was chosen. Given the small sample size, the Fisher exact test was performed to calculate the crude odds ratio (OR), significance level, and 95\% confidence intervals (CIs). Multivariate logistic regressions controlling for exposure hours were performed in secondary analysis for significant findings to yield adjusted ORs. We chose this method becaue it had been successfully employed to assess risk factors for injury in pediatric climbers ${ }^{3,6}$ and would allow our results to be compared against data from the most recent related meta-analysis. Independent $t$ tests were used where appropriate for continuous vs categorical data, and Pearson's correlation scatterplots were created for purely continuous data. 
Statistical testing was performed using data obtained from our institutional REDCap survey tool and the statistical software JASP 2020 (Version 0.12.2).

\section{Results}

Fifty-two respondents aged 7 to 18 y completed all mandatory portions of the survey. Six participants completed only demographic sections, and 2 answered limited questions about climbing time but provided no injury data and thus were excluded. Table 1 summarizes participant characteristics and participation. Digital survey distribution strategies resulted in a response rate of $67 \%$, although because this was calculated as "unique clicks" vs "completed surveys," it likely overestimates the true response rate. Thirty-four participants (65\%) reported competing at least at the regional level of competition; all competed in local competitions or higher. Respondents reported climbing $2.5 \pm 0.6 \mathrm{~h}$ per session and approximately $389 \pm 191 \mathrm{~h} \cdot \mathrm{y}^{-1}$.

Twenty-two climbers (42\%) reported an acute injury. Of these, $6(12 \%)$ were re-injuries after previous recovery, and $7(14 \%)$ reported multiple acute injuries. When chronic injuries were added, 34 climbers $(65 \%)$ reported a new injury. Fifty-two participants recorded a total of 56 injuries, resulting in an injury proportion of 108 per 100 athletes. The overall injury rate was 2.9 per 1000 participation hours. The injury rate was 1.7 per 1000 participation hours when considering only acute injuries (Table 2).

Hand/Finger injuries represented the most common type of injuries reported (36\%). Other body areas injured included elbow and wrist (13\% each); head (8\%); hip/ pelvis, shoulder, and lower leg/ankle (5\% each); neck and foot/toe ( $4 \%$ each); and thigh and knee ( $2 \%$ each). No facial, dental, back, or chest injuries were reported. Equal numbers of sprain/strain, tendinitis/tendinosis, and pulley injuries were reported (9 each). Four concussions and 3 fractures were reported. Overuse/Repetitive stress injuries were the most commonly reported mechanism (70\%). Other mechanisms included falls (14\%) and performing a large/strenuous move off of a small hold (14\%).

In regard to treatment for injuries, self-performed or coach-assisted aid without involvement of medical personnel was most common (first-aid, taping $=44 \%$ of treatments), followed by outpatient physician visit (27\%) and physical therapy (17\%). Three required emergency department visits, and 1 required surgical intervention.

Overall, 31 injuries $(55 \%)$ resulted in at least $1 \mathrm{~d}$ of climbing time lost. For acute injuries, the most common amount of time taken off was 1 to 4 wk (15 climbers), whereas chronic injuries/ongoing pain resulted in most climbers taking no time off.
Table 1. Baseline characteristics and demographics

\begin{tabular}{|c|c|c|}
\hline Characteristic & $n(\%)$ & $\begin{array}{l}\text { Mean } \pm S D \text { or } \\
\text { Median }(I Q R)\end{array}$ \\
\hline Total participants & 52 & \\
\hline \multicolumn{3}{|l|}{ Sex } \\
\hline Male & $23(44)$ & \\
\hline Female & $29(55)$ & \\
\hline Age (y) & & $14 \pm 3$ \\
\hline $5-7$ & $0(0)$ & \\
\hline $8-9$ & $3(6)$ & \\
\hline $10-11$ & 7 (14) & \\
\hline $12-13$ & $11(21)$ & \\
\hline $14-15$ & $12(23)$ & \\
\hline $16-17$ & $8(15)$ & \\
\hline 18 & $11(21)$ & \\
\hline Body mass index $\left(\mathrm{kg} \cdot \mathrm{m}^{-2}\right)$ & & $19.0 \pm 2.6$ \\
\hline Member of USA Climbing & $34(65)$ & \\
\hline $\begin{array}{l}\text { Competes at more than local } \\
\text { level }\end{array}$ & $34(65)$ & \\
\hline Climbing hours per session & & $2.5 \pm 0.6$ \\
\hline Climbing hours per year & & $389 \pm 191$ \\
\hline $\begin{array}{l}\text { Bouldering difficulty (Hueco } \\
\text { scale) }\end{array}$ & & V5-V6 (V4-V7) \\
\hline $\begin{array}{l}\text { Sport climbing difficulty } \\
\text { (Yosemite decimal scale) }\end{array}$ & & $\begin{array}{l}5.11 \mathrm{c}-5.11 \mathrm{~d} \\
(5.11 \mathrm{a}-5.12 \mathrm{a})\end{array}$ \\
\hline Teams represented & 20 & \\
\hline
\end{tabular}

Ninety-one percent of reported acute injuries occurred during bouldering $(P<0.001)$. Bouldering difficulty was also associated with self-reported injury; athletes who reported injuries also reported climbing more difficult problems/routes (V5 and below vs V6 and above, $P=0.04)$. Total reported injury number increased similarly $(\mathrm{R}=0.33,95 \% \mathrm{CI} 0.06-0.55, P=0.02)$. These results remained significant when controlled for exposure hours $(P=0.03)$. Sport/Lead climbing difficulty was not associated with increased risk in our limited data set. As climbing time per year increased, so did the report of any climbing-related injury $(P=0.001)$. Climbers were also more likely to report injuries if their sessions were longer, especially $>2 \mathrm{~h}$ in a single session $(P<0.001)$.

Another potentially significant risk factor was return to climbing while still injured or in pain. Fifty-two percent reported climbing while in pain or returning after suspected injury while still hurting. Early return increased the odds of any reported injury (OR 24.4, 95\% CI 4.6-130.1, $P<0.001$ ), acute injury (OR 3.5, 95\% CI $1.1-11.3, P<0.04)$, and chronic injury (OR $15.5,95 \% \mathrm{CI}$ 3.8-66.7, $P<0.001)$ after controlling for climbing exposure hours. Our small group of athletes reported varying reasons for premature return, including a belief that the injury was minor (29\%), fear of losing climbing skills (25\%), concern about upcoming competition (25\%), fear 
Table 2. Injury rates and patterns

\begin{tabular}{|c|c|}
\hline Injury pattern & $\begin{array}{l}\text { Injury rate, injuries per } \\
1000 \text { climbing hours }\end{array}$ \\
\hline Total & 2.9 \\
\hline Acute injuries only & 1.7 \\
\hline Injured climbers & $\mathrm{n}(\%$ of climbers $)$ \\
\hline Total & $34(65)$ \\
\hline Any acute injury & $22(42)$ \\
\hline Multiple acute injuries & 7 (14) \\
\hline $\begin{array}{l}\text { Chronic injuries/significant } \\
\text { climbing-related pain }\end{array}$ & $24(46)$ \\
\hline $\begin{array}{l}\text { Reinjury after previous } \\
\text { complete recovery }\end{array}$ & $6(12)$ \\
\hline Injury number & $\mathrm{n}(\%$ of injuries $)$ \\
\hline Total & $56 ;$ mean $=1 /$ climber, SD 1 \\
\hline Acute injuries & $34(61)$ \\
\hline $\begin{array}{l}\text { Chronic injuries/significant } \\
\text { climbing-related pain }\end{array}$ & $22(39)$ \\
\hline Anatomic location of injuries & $\mathrm{n}(\%$ of injuries) \\
\hline Head & $4(8)$ \\
\hline Acute & 4 \\
\hline Chronic & 0 \\
\hline Face/Mouth & $0(0)$ \\
\hline Neck & $2(4)$ \\
\hline Acute & 1 \\
\hline Chronic & 1 \\
\hline Chest & $0(0)$ \\
\hline Shoulder & $3(5)$ \\
\hline Acute & 1 \\
\hline Chronic & 2 \\
\hline Upper arm & $0(0)$ \\
\hline Elbow & $7(13)$ \\
\hline Acute & 5 \\
\hline Chronic & 2 \\
\hline Forearm/Wrist & $7(13)$ \\
\hline Acute & 6 \\
\hline Chronic & 1 \\
\hline Hand/Finger & $20(36)$ \\
\hline Acute & 9 \\
\hline Chronic & 11 \\
\hline Hips/Pelvis & $3(5)$ \\
\hline Acute & 2 \\
\hline Chronic & 1 \\
\hline Thigh/Upper leg & $1(2)$ \\
\hline Acute & 1 \\
\hline Chronic & 0 \\
\hline Knee & $1(2)$ \\
\hline Acute & 1 \\
\hline Chronic & 0 \\
\hline Lower leg/Ankle & $3(5)$ \\
\hline Acute & 2 \\
\hline Chronic & 1 \\
\hline Foot/Toe & $2(4)$ \\
\hline Acute & 1 \\
\hline Chronic & 1 \\
\hline
\end{tabular}

(continued)
Table 2 (continued)

\begin{tabular}{lc}
\hline Injury pattern & $\begin{array}{c}\text { Injury rate, injuries per } \\
1000 \text { climbing hours }\end{array}$ \\
\hline Acute injury type & $\mathrm{n}(\%$ of injuries $)$ \\
Sprain/Strain & $9(27)$ \\
Tendinitis/Tendinosis & $9(27)$ \\
Pulley injury/rupture & $9(27)$ \\
Concussion & $4(12)$ \\
Fracture & $3(9)$ \\
Mechanism of all injuries & $\mathrm{n}(\%$ of injuries $)$ \\
$\quad$ (acute and chronic) & $39(70)$ \\
Overuse/Repetitive Stress & $8(14)$ \\
Fall & $8(14)$ \\
Large/Strenuous move off of & $1(2)$ \\
$\quad$ small hold & $\mathrm{n}(\% \text { of treatments tried })^{a}$ \\
Not specified & \\
Treatments required for & $2(3)$ \\
$\quad$ injuries & $16(21)$ \\
None & $18(23)$ \\
Self-administered first aid & $21(27)$ \\
Taping & \\
Visit to pediatrician & \\
orthopedist, or sports & $3(4)$ \\
medicine & $3(17)$ \\
Visit to emergency department & \\
Cast or splint & \\
Physical therapy & \\
Surgery & \\
\hline${ }^{a}$ More than 1 response accepted. & \\
&
\end{tabular}

of losing a spot on a climbing team (10\%), peer pressure $(10 \%)$, and pressure from a coach or parent $(3 \%)$.

Use of finger taping as a preventative measure increased the odds of reported injury by a factor of 1.4 (95\% CI 1.4-4.5, $P=0.04$ ) when adjusted for climbing hours.

A statistically significant association between percentage of time an athlete spends climbing under direct adult supervision and injury was suggested for both bouldering and lead climbing (Figures 1 and 2).

Current age, age at which the athlete began competing, sex, other sport participation, other sport injury, level of competition, safety skills taught by the team or learned outside of the team setting, use of a hang board training device, presence of past medical conditions, and warming up/cooling down were not statistically associated with increased or decreased odds of injury generally nor any subcategory of injury in our limited data set (Table 3).

\section{Discussion}

Our study attempts to add data to the growing body of literature examining rate, proportion, types, and mechanisms of injury and risk factors for injury in competitive 


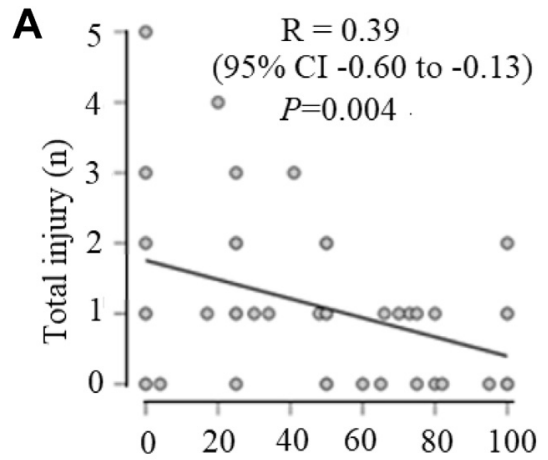

Supervised bouldering time (\%)

\section{B}

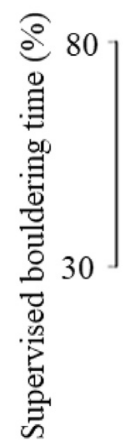

Figure 1. (A) Supervised bouldering time vs total injury number. (B) Mean difference in development of a climbing-related injury vs percentage of time spent bouldering while supervised.

youth climbers, but it is vital to reiterate that all data are both self-reported and from an extremely small sample of climbers. Although lead climbing and bouldering tend to be male dominated at the elite level, the demographics of the sport are changing rapidly. Our study had nearly equal numbers of male and female participants, which may represent this change or may represent a bias in surveying. Despite the small number of participants and low response rate, which limit broad interpretation of our results, we were able to obtain data from a wide geographic area representing 20 climbing teams in all regions of the United States and climbers competing at different levels.

Injury types reported were consistent with those described in other available climbing literature, with hand/finger injuries dominating. , $3,6-16^{\text {Repetitive/ }}$ Overuse was the most common self-reported mechanism of injury, consistent with many other studies on the subject, despite the vagueness of the phrase "repetitive overuse." Falls and making a large move were also commonly reported mechanisms, again consistent with previous data. ${ }^{4,12,14,17-19}$
Most injuries reported in this small study required little time away from climbing. It is unclear whether this was due to mild severity, earlier return than appropriate, a combination of both, or the small sample of respondents and recall bias. The lack of time away and overwhelming treatment with first aid and outpatient visits suggests that severe acute injury is rare in elite youth climbers.

Our injury rate (2.9 per 1000 climbing hours) was lower than previously reported for elite youth climbers ${ }^{6}$ but still within the range reported in a recent meta-analysis on youth climbing injuries. ${ }^{2}$ Our lower injury rate might be due to our small sample, underreporting of minor or chronic injuries by the athletes, or failure to recall these injuries. Our self-reported injury rate could also be an overreporting based on the specific nature of the questions we asked. Overall, our injury rate is close to that among competitive youth swimming/diving and track and field and much lower than the reported injury rate for football, hockey, soccer, and basketball. ${ }^{19}$

Previous studies have shown mean ages of competitive youth climbers in their late teens. This was consistent with our study as well; our youngest participants were $8 \mathrm{y}$ old $(\mathrm{n}=3)$, and multiple children aged $\leq 11$ y participated, but $20 \%$ of respondents were aged $18 \mathrm{y}$. We do not yet
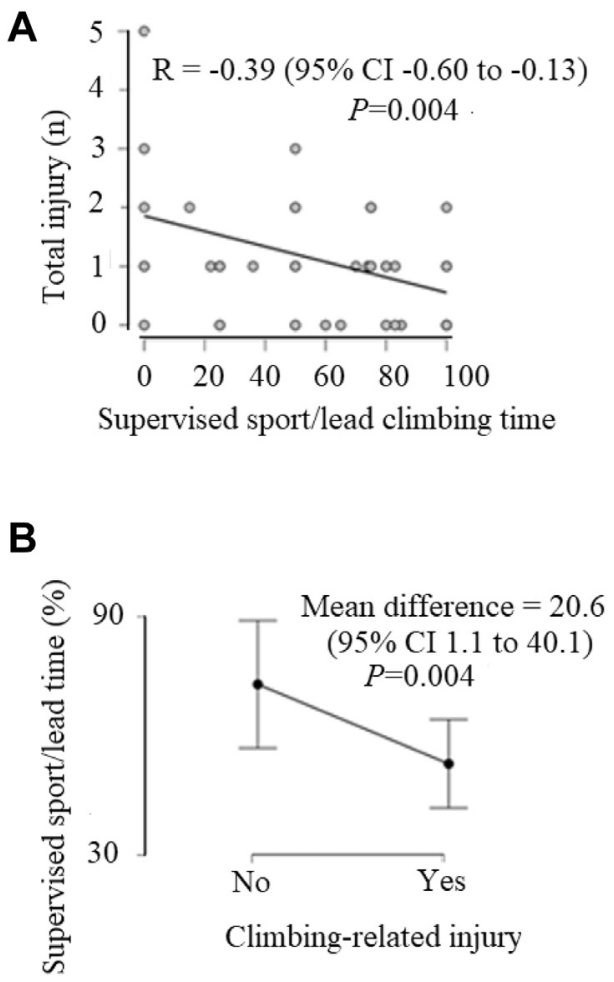

Figure 2. (A) Supervised sport/lead climbing time vs total injury number. (B) Mean difference in development of a climbing-related injury vs percentage of time spent sport climbing while supervised. 
Table 3. Variables and their association with injury

\begin{tabular}{|c|c|c|c|c|}
\hline Variable & $\begin{array}{l}\text { Odds ratio }(O R) \\
(95 \% \text { confidence interval })\end{array}$ & $\mathrm{P}$ value & $\begin{array}{c}\text { Adjusted OR } \\
(95 \% \text { confidence interval) }\end{array}$ & $\begin{array}{l}\text { Adjusted } \\
\mathrm{P} \text { value }\end{array}$ \\
\hline \multicolumn{5}{|l|}{ Member of USA Climbing } \\
\hline Any injury or significant climbing-related pain & $2.8(0.8-9.2)$ & 0.13 & - & - \\
\hline Acute injury (at least 1 ) & $1.2(0.3-2.6)$ & 0.78 & - & - \\
\hline Acute injuries (multiple) & $3.0(0.6-15.0)$ & 0.22 & - & - \\
\hline Chronic injuries/pain & $2.8(4.5-88.9)$ & 0.13 & - & - \\
\hline \multicolumn{5}{|l|}{ Returned to climbing while still injured or in pain } \\
\hline Any injury or significant climbing-related pain & $24.3(4.6-130.1)$ & $<0.001^{a}$ & $52.5(4.9-567.8)$ & $<0.001^{a}$ \\
\hline Acute injury (at least 1 ) & $3.5(1.1-11.3)$ & $0.04^{b}$ & $1.6(0.3-6.2)$ & 0.06 \\
\hline Acute injuries (multiple) & $2.5(4.9-15.7)$ & 0.42 & $3.4(0.6-21.0)$ & 0.14 \\
\hline Chronic injuries/pain & $15.5(3.8-66.7)$ & $<0.001^{a}$ & $18.3(3.9-87.5)$ & $<0.001^{a}$ \\
\hline \multicolumn{5}{|l|}{ Plays other sports } \\
\hline Any injury or significant climbing-related pain & $0.6(0.2-2.0)$ & 0.56 & - & - \\
\hline Acute injury (at least 1 ) & $1.0(0.3-3.0)$ & 0.96 & - & - \\
\hline Acute injuries (multiple) & $1.1(0.2-5.6)$ & 0.89 & - & - \\
\hline Chronic injuries/pain & $0.7(0.2-2.3)$ & 0.78 & - & - \\
\hline \multicolumn{5}{|l|}{ Safety skills taught by team } \\
\hline Any injury or significant climbing-related pain & $1.4(0.2-9.1)$ & 1.00 & - & - \\
\hline Acute injury (at least 1 ) & $0.5(0.1-3.1)$ & 0.64 & - & - \\
\hline Acute injuries (multiple) & $0.2(0.2-1.4)$ & 0.13 & - & - \\
\hline Chronic injuries/pain & $3.4(0.3-32.4)$ & 0.38 & - & - \\
\hline \multicolumn{5}{|l|}{ Safety skills learned outside of team setting } \\
\hline Any injury or significant climbing-related pain & $4.1(0.9-17.3)$ & 0.07 & - & - \\
\hline Acute injury (at least 1 ) & $2.0(0.5-8.9)$ & 0.48 & - & - \\
\hline Acute injuries (multiple) & $3.9(0.7-21.7)$ & 0.126 & - & - \\
\hline Chronic injuries/pain & $3.8(0.7-20.2)$ & 0.16 & - & - \\
\hline \multicolumn{5}{|l|}{ Use of hang board at home } \\
\hline Any injury or significant climbing-related pain & $3.4(1.0-11.6)$ & 0.07 & - & - \\
\hline Acute injury (at least 1 ) & $1.2(0.4-3.9)$ & 0.78 & - & - \\
\hline Acute injuries (multiple) & $4.6(0.5-41.1)$ & 0.22 & - & - \\
\hline Chronic injuries/pain & $2.9(0.9-9.4)$ & 0.16 & - & - \\
\hline \multicolumn{5}{|l|}{ Warming up before practice } \\
\hline Any injury or significant climbing-related pain & $1.9(0.1-32.9)$ & 0.65 & - & - \\
\hline Acute injury (at least 1 ) & $0.8(0.9-1.1)$ & 0.89 & - & - \\
\hline Acute injuries (multiple) & $5.9(0.3-99.4)$ & 0.40 & - & - \\
\hline Chronic injuries/pain & $0.8(0.1-12.9)$ & 0.89 & - & - \\
\hline \multicolumn{5}{|l|}{ Cooling down after practice } \\
\hline Any injury or significant climbing-related pain & $0.5(0.2-1.6)$ & 0.25 & - & - \\
\hline Acute injury (at least 1 ) & $1.1(0.3-2.9)$ & 0.84 & - & - \\
\hline Acute injuries (multiple) & $0.4(0.1-2.3)$ & 0.42 & - & - \\
\hline Chronic injuries/pain & $0.5(0.2-1.4)$ & 0.26 & - & - \\
\hline \multicolumn{5}{|l|}{ Use of finger taping for injury prevention } \\
\hline Any injury or climbing-related pain & $2.5(0.7-9.0)$ & 0.23 & $1.4(1.1-4.5)$ & $0.02^{b}$ \\
\hline Acute injury (at least 1 ) & $1.2(0.4-4.0)$ & 0.78 & $0.6(0.2-2.1)$ & 0.24 \\
\hline Acute injuries (multiple) & $0.3(0.03-2.5)$ & 0.40 & $0.3(0.03-3.3)$ & 0.39 \\
\hline Chronic injuries/pain & $5.1(1.5-17.0)$ & $0.01^{b}$ & $4.3(1.2-15.2)$ & $0.03^{b}$ \\
\hline \multicolumn{5}{|l|}{$\begin{array}{l}\text { Competing at higher than the recreational or local } \\
\text { level }\end{array}$} \\
\hline Any injury or climbing-related pain & $6.0(1.7-21.3)$ & $0.01^{b}$ & $2.0(0.5-7.8)$ & 0.33 \\
\hline Acute injury (at least 1 ) & $3.2(0.9-11.0)$ & 0.07 & $0.5(0.2-1.9)$ & 0.33 \\
\hline Acute injuries (multiple) & $0.4(0.1-2.0)$ & 0.25 & $1.6(0.3-10.0)$ & 0.62 \\
\hline Chronic injuries/pain & $2.8(0.7-6.8)$ & 0.08 & $1.8(0.5-6.7)$ & 0.34 \\
\hline
\end{tabular}

\footnotetext{
${ }^{a}$ designates $\mathrm{P}<0.01$.
}

${ }^{b}$ designates $\mathrm{P}<0.05$. 
know the full impact of climbing-related epiphyseal injuries, nor do we understand the relationship between age-related developmental choices (eg, risk-taking behavior and peer influence) and their effects on injuries, so this could be an area to explore in further research.

This study attempts to elucidate the details of how returning to climbing while still injured affects climbingrelated injuries. The reliance on self-reported data, small sample, and high likelihood of confounders limits broad interpretation, but given the persistent association between early return to climbing and increased injury risk and the larger effect size than expected seen in our study when controlling for exposure, this may still be clinically meaningful. Our study also begins to evaluate the athletes' own reasons for returning while in pain, and better understanding of the developmental psychology of these climbers may help influence how to best mediate these risks while discussing their specific fears and desires in an age-appropriate manner.

Because $91 \%$ of reported acute injuries occurred during bouldering, and bouldering difficulty also increased the risk of reported injury, these limited data suggest that bouldering itself may be an independent risk factor, perhaps owing to the dynamic forces involved in bouldering and the fall potential, and could be further evaluated in subsequent studies. Direct supervision of athletes appeared to decrease the risk of injury. These relationships represent an area of injury prevention to explore with more robust studies than ours and may help shape future training and competition planning.

Overall, the factors most associated with increased risk of reported injury when adjusted for confounders were returning to climbing while still injured or in pain, total number of hours climbed per year, unsupervised climbing, and use of finger taping as a preventative measure. Finger taping has previously been associated with increased injury risk, ${ }^{6}$ and we speculate that climbers use the tape as a way to return to activity prematurely, resulting in an increased risk of chronic injury.

The factors associated with increased total number of reported injuries were bouldering difficulty, climbing unsupervised, and a higher number of climbing hours per session. Even when difficulty and supervision were adjusted for climbing exposure hours and athlete age, they remained significant.

\section{LIMITATIONS}

The sample size of our study is the most limiting factor, severely limiting the confidence and applicability of the study. Because of the distribution methodology, we are unable to determine how many climbers did not open the survey; the nonresponse rate only represents those who clicked the link but did not complete the survey. The survey link was posted online and sent to athletes by coaches, creating additional selection bias. The impact of these factors on our statistics and their generalizability is unknown but creates significant bias and difficulty in interpreting the data and associated statistics presented.

The timing of this study led to significant limitations as well. Surveys were sent out in February 2020, when the scope of the COVID-19 pandemic was not yet known. Data collection finished in April 2020. Lockdowns limited access to potential participants, and because only electronic responses could be obtained, internet access could have limited accessibility for survey completion.

This study relied on cross-sectional, retrospective, self-reported data, and thus establishing causal relationships is not possible. The design can only be used to give the odds of injury in relation to risk factors. Our small sample size produced large ORs with very wide CIs; acceptance of results at even the lowest limits of the CI should be done extremely cautiously.

Climbers and their parents were asked to remember minor injuries over 12 mo, introducing recall bias. The young age of the children included also may have led to reporting bias, even if the athletes' parents assisted. The older age of many of our participants is limiting as well: $20 \%$ of respondents were 18 y old, which limits application of the limited data gathered to the broader youth climbing community. Because coaches were involved in the distribution of the survey, athletes may have felt "pressured" to complete it, introducing another source of potential reporting bias. Exclusion of climbers who were not competitive in the past 12 mo may also have underestimated the number of severe injuries owing to sport dropout if these injuries were career-ending.

The injury data are also subject to self-diagnosis. The majority of respondents in our limited sample treated their injuries without the aid of a medical professional, and although attempts were made to objectively categorize injuries, self-report in a very small total number of respondents remains inherently limited, especially when using these data to calculate injury rates.

\section{Conclusions}

Our study adds data, albeit limited, to the growing body of literature on injuries in pediatric competitive climbers. The overall climbing injury rate was lower than previously reported, and repetitive overuse represented the most common mechanism. Bouldering and total climbing hours were risk factors for reported injury. Cumulative 
climbing time may increase risk of injury. Hand/Finger injuries predominated reported injury types.

Returning to climbing while still in pain and the risk of injury appeared to be related as well. Understanding the young athlete's unique developmental psychology and identifying opportunities for injury prevention in this realm may represent an area of interest for future researchers to develop injury prevention techniques.

Further examination of the modifiable risk factors this small study suggest, such as early return to climbing, finger taping, discipline, difficulty level, climbing time, and supervision, may be useful to aid in the development of robust, unified injury prevention strategies. Larger, prospective studies can be performed.

Acknowledgments: The division of pediatric emergency medicine at UT Southwestern Medical Center was instrumental in the vision, implementation, and analysis of this study. We acknowledge Kaikanani Woolings of the University of Calgary for sharing the climbing questionnaire. Thanks to Team Texas, Team Summit, the First Ascent Climbing Team, and all other teams, participants, and parents/guardians who helped facilitate this important research.

Previous Presentation of Work: An overview of this manuscript was presented as an oral presentation at the Division of Pediatrics Senior Fellow Research Day, May 19, 2020, at UT Southwestern Medical Center in Dallas, Texas.

Author Contributions: Study concept and design, obtaining funding, acquisition of data, analysis of data, drafting of the manuscript, critical revision of the manuscript $(\mathrm{AB})$ review of the manuscript $(\mathrm{SF}, \mathrm{JN}, \mathrm{CH})$ review of data analysis $(\mathrm{JN})$ approval of final manuscript $(\mathrm{AB}, \mathrm{SF}, \mathrm{JN}$, $\mathrm{CH})$

Financial/Material Support: None.

Disclosures: None.

\section{References}

1. Schlegel C, Buechler U, Kriemler S. Finger injuries of young elite rock climbers. Schweiz Z Med Traumatol. 2002;50(1):7-10.

2. Morrison AB, Schöffl VR. Review of the physiological responses to rock climbing in young climbers. $\mathrm{Br} J$ Sports Med. 2007;45(3):852-61.

3. Schöffl VR, Lutter C, Woollings K, Schöffl I. Pediatric and adolescent injury in rock climbing. Res Sports Med. 2018;26(suppl 1):91-113.
4. Schöffl VR, Burtscher E, Coscia F. Injuries and medical incidences during the IFSC 2012 climbing world cup series. Medica Sport. 2013;17(4):168-70.

5. Neuhof A, Hennig FF, Schöffl I, Schöffl VR. Injury risk evaluation in sport climbing. Int J Sports Med. 2011;32(10):794-800.

6. Woollings KY, McKay CD, Kang J, Meeuwisse WH, Emery CA. Incidence, mechanism and risk factors for injury in youth rock climbers. Brit J Sports Med. 2015;49(1):44-50.

7. Jones G, Johnson M. A critical review of the incidence and risk factors for finger injuries in rock climbing. Curr Sports Med Rep. 2016;15(6):400-9.

8. Schöffl VR, Hoffmann G, Küpper T. Acute injury risk and severity in indoor climbing-a prospective analysis of 515,337 indoor climbing wall visits in 5 years. Wilderness Environ Med. 2013;24(3):187-94.

9. Woollings KY, McKay CD, Emery CA. Risk factors for injury in sport climbing and bouldering: a systematic review of the literature. Br J Sports Med. 2015;49(17):1094-9.

10. Wright DM, Royle TJ, Marshall T. Indoor rock climbing: who gets injured? Br J Sports Med. 2001;35(3):181-5.

11. Backe S, Ericson L, Janson S, Timpka T. Rock climbing injury rates and associated risk factors in a general climbing population. Scand J Med Sci Sports. 2009;19(6):850-6.

12. Folkl AK. Characterizing the consequences of chronic climbingrelated injury in sport climbers and boulderers. Wilderness Environ Med. 2013;24(2):153-8.

13. Nelson NG, McKenzie LB. Rock climbing injuries treated in emergency departments in the U.S., 1990-2007. Am J Prev Med. 2009;37(3):195-200.

14. Hohlrieder M, Lutz M, Schubert H, Eschertzhuber S, Mair P. Pattern of injury after rock-climbing falls is not determined by harness type. Wilderness Environ Med. 2007;18(1):30-5.

15. Jones G, Asghar A, Llewellyn DJ. The epidemiology of rockclimbing injuries. Brit J Sports Med. 2008;42(9):773-8.

16. Lutter C, El-Sheikh Y, Schöffl I, Schöffl V. Sport climbing: medical considerations for this new Olympic discipline. Brit J Sports Med. 2017;51(1):2-3.

17. Rooks MD. Rock climbing injuries. Sports Med. 1997;23(4):261-70.

18. Von Rosen P, Kottorp A, Fridén C, Frohm A, Heijne A. Young, talented and injured: Injury perceptions, experiences and consequences in adolescent elite athletes. Eur J Sport Sci. 2018;18(5): 731-40.

19. Kerr Z, Marshall SW, Dompier TP, Corlette J, Klossner DA, Gilchrist J. College sports-related injuries - United States, 2009-10 through 2013-14 academic years. MMRW Morb Mortal Wkly Rep. 2015;64(48):1330-6. 